\title{
Experimental study of multi-timescale crack blunting in hydraulic fracture
}

\author{
Jing-Nan Dong ${ }^{1,2,3} \cdot$ Guang-Jie Yuan $^{3} \cdot$ Xiang-Yang Wang $^{3} \cdot$ Mian Chen $^{1,2} \cdot$ Yan Jin $^{1,2} \cdot$ Chao Zeng ${ }^{4}$ Musharraf Zaman $^{5}$
}

Received: 27 February 2020 / Published online: 13 July 2020

(c) The Author(s) 2020

\begin{abstract}
Hydraulic fracture is important in unconventional oil and gas exploration. During the propagation of the hydraulic fracture, the crack tip is blunted due to the development of the process zone in the near-tip area. In this study, the blunting of the hydraulic fracture in polymethyl methacrylate specimens due to multi-timescale stress concentration is investigated. The ratio of the initiation toughness to the arrest toughness of the blunted hydraulic fracture is measured using both the dynamic and the static methods. Results show that a hydraulic fracture can be blunted with the time span of stress concentration from $1 \mathrm{~ms}$ to $600 \mathrm{~s}$. It is also shown that the blunting of hydraulic fracture is a highly localized process. The morphology of the blunted crack depends on the stress distribution in the vicinity of the crack tip.
\end{abstract}

Keywords Hydraulic fracture · Crack blunting · Crack tip morphology

\section{Introduction}

Hydraulic fracture is essential in unconventional oil and gas exploration such as the exploration of shale gas. Despite significant accomplishments in successful applications of hydraulic fracturing in the oil industry, there are still some fundamental questions that need to be resolved (Ai et al. 2018; Tan et al. 2019). Hydraulic fracturing process is

Edited by Yan-Hua Sun

Mian Chen

chenmian@vip.163.com

Jing-Nan Dong

15210877909@163.com

1 State Key Laboratory of Petroleum Resources and Prospecting (Beijing), Beijing 102249, China

2 College of Petroleum Engineering, China University of Petroleum, Beijing 102249, China

3 CNPC Engineering Technology R\&D Company Limited, Beijing 102206, China

4 Department of Civil, Architectural and Environmental Engineering, Missouri University of Sciences and Technology, Rolla, MO, USA

5 Mewbourne School of Petroleum and Geological Engineering, University of Oklahoma, Norman, OK 73019, USA essentially a dynamic process. Even the controlled and overall stable hydraulic fracture propagation is unstable at the small scale (Germanovich et al. 1997). Recent dynamic analyses based on numerical approaches show that the hydraulic fracture propagates in a stepwise manner (Cao et al. 2018) in both dynamic situation and quasi-static situation. There are also experimental evidences showing that the hydraulic fracture in hydrogels is stepwise (Pizzocolo et al. 2013). In this study, we investigate the crack blunting, which is a possible reason for the propagation of hydraulic fracture in a stepwise manner.

The blunting or reducing of hydraulic fracture mainly results from the near-tip stress concentration, which leads to the development of the process zone. In geomaterial such as shale, the process zone exists in the way of fissure swarm (Anderson 2005; Dong et al. 2019b; Li et al. 2020). In polymers such as polymethyl methacrylate (PMMA), the development of process zone is named as "crazing". The mechanisms of the development of the process zone are fundamentally the same. The stresses in these areas exceed the yield stress and the material exhibits yielding, either in the way of micro-crack propagation (rock) or the development of the cohesive zone (polymer). The development of the process zone results in stress shielding around the crack tip and the crack tip is thus blunted.

The blunting of dry Mode I fracture tip due to stress concentration is well studied. In previous experimental 
studies, two methods have been commonly used to blunt or increase the fracture toughness of the crack. The first method uses cyclic loading. For example, Radon et al. (1976) used cyclic load at different frequencies to blunt the crack tip. It was found that it is easier to blunt a crack at low frequency $(0.25 \mathrm{~Hz})$ than at high frequency $(35 \mathrm{~Hz})$. The second method uses static loading. In a study by Kinloch and Williams (1980), 86\% of the failure load was applied to the crack and was held for different time spans varying from $1 \mathrm{~s}$ to 600 days. In both methods, the blunting of crack is characterized by the ratio of the initiation toughness to the arrest toughness. In recent studies, researchers have focused their attention more on the fundamental mechanism(s) of crack blunting. Molecular dynamic simulation is becoming more and more popular as it reveals the intrinsic properties of a material (Rajan and Curtin 2016). Dislocation is also considered closely related to the crack blunting (Beltz et al. 1999; Fischer and Beltz 2001). Generation of dislocations from the tip is generally considered a major reason of ductile crack blunting (Shiari and Miller 2016).

In a hydraulic fracture, the crack tip is blunted by the development of the process zone. To the authors' knowledge, no experiment has ever been conducted on crack blunting of hydraulic fracture. According to our observations, the crack blunting does not proceed if the hydraulic pressure is not high enough. This phenomenon has also been seen in tensile tests by Luo et al. (2014). According to these researchers, significant blunting only occurs when the tensile fracture stress is larger than some certain value. In terms of numerical simulation, finite element method (FEM), extended finite element method (XFEM) and distinct element method (DEM) are often applied in the numerical modeling of hydraulic fractures. Salimzadeh and Khalili (2015a, b) proposed a hydro-mechanical model for hydraulic fracturing. To the authors' knowledge, no simulation considering crack blunting in hydraulic fracture was conducted. The present study can be implemented in the numerical simulation considering the crack blunting during the propagation of the hydraulic fracture.

In the present study, experiments on crack tip blunting of hydraulic fracture are conducted. Both dynamic and static crack blunting are studied. A high-speed camera is used to capture the dynamic propagation of hydraulic fracture. In dynamic analysis, beam theory is applied to determine the ratio of initiation toughness to arrest toughness. In static experiments, the static pressure is applied to induce crack blunting and the fracture toughness of hydraulic fracturing in double cantilever beam (HF-DCB) specimens is measured. The morphology of the blunted crack tip is characterized using an optical microscope $(\mathrm{OM})$.

\section{Experimental setup}

In this section, the experimental setup was briefly introduced. A meso-scale hydraulic fracture device was built. Two transparent PMMA boards were used as the frame structure. In order to seal the hydraulic fluid from leaking, two silicone sealing strips, one on each side of the specimen surface, were used. Silicone seals offered great performance in unconventional sealing situations at a low pressure. Three alignment steel boards were installed to adjust the position of the PMMA specimens. The following hydraulic and controlling systems, manufactured by GCTS, the RTR-1500 hydraulic system and SCON controlling system, respectively, were used.

The elastic modulus of the PMMA specimen is 2.6 $\mathrm{GPa}$, and Poisson's ratio is 0.33 . The geometrical parameters are shown in Fig. 1a. The thickness of the specimen is $b=5.0 \mathrm{~mm} \pm 0.1 \mathrm{~mm}$. Two kinds of crack tips were studied. One is a artificial crack tip of $0.5 \mathrm{~mm}$ width produced by laser cutting, while the other is an intrinsically sharp crack tip produced by a Chevron notch on a regular DCB machine. The natural sharp crack length is $35 \mathrm{~mm} \pm 2 \mathrm{~mm}$.

In order to capture the crack propagation, both optical microscope $(\mathrm{OM})$ and high-speed cameras were used. The resolution of the OM photo is $1624 \times 1236$. The sampling interval of the high-speed camera is $5 \mu \mathrm{s}$.

During the experiments, the fracturing fluid (water) was injected into the void between the two beams of the specimen. In the dynamic situation, the pressure of the fluid was increased until the crack started to propagate. In the quasistatic situation, the pressure of the fluid was increased to some certain value, and was kept for some time, after which the pressure was further increased to initiate the crack.

\section{Crack blunting due to multi-time-scale stress concentration}

\subsection{Short-time dynamic stress concentration}

In order to characterize the short-time crack blunting under dynamic loading, the initiation toughness of the intrinsically sharp hydraulic crack subjected to different short-time stress concentration is measured. The stress concentration due to hydraulic pressure as small as $1 \mathrm{~ms}$ is studied. The ratio of energy release rate $\eta$ is defined as

$\eta=G_{\mathrm{i}} / G_{\mathrm{a}}$

where $G_{\mathrm{i}}$ is the initiation energy release rate; and $G_{\mathrm{a}}$ is the energy release rate at crack arrest. Thus, the degree of bluntness $\sqrt{\eta}$ could be expressed as 

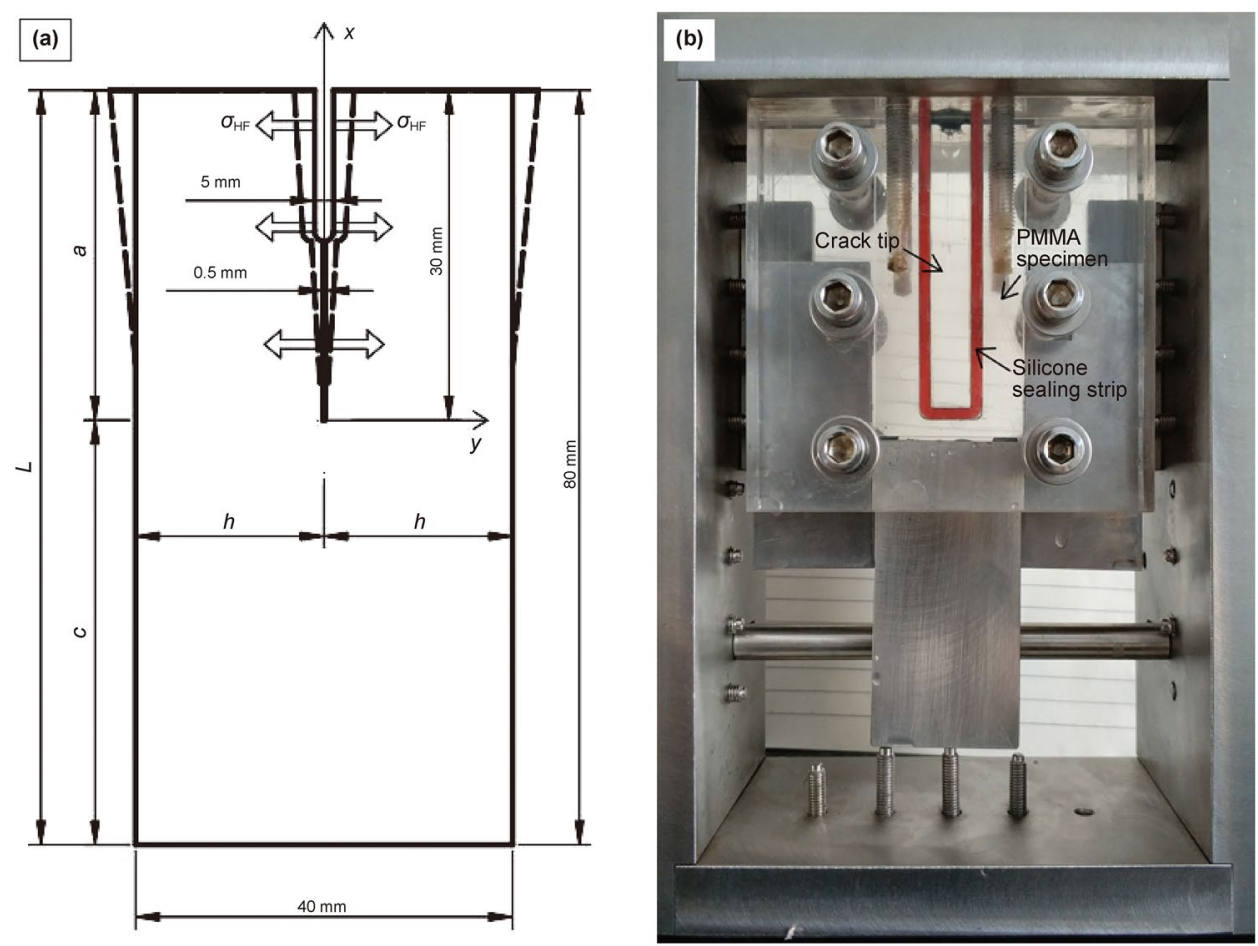

Fig. 1 Experimental setup. a Specimen and $\mathbf{b}$ hydraulic fracturing device. The experimental setup is largely the same as the device and specimen described by Dong et al. (2019a, 2020)

$\sqrt{\eta}=K_{\mathrm{i}} / K_{\mathrm{a}}$

where $K_{\mathrm{i}}$ is the initiation toughness; and $K_{\mathrm{a}}$ is the arrest toughness.

In order to obtain the value of $\sqrt{\eta}$, the beam theory is applied. The model is based on the quasi-static treatment of unstable propagation in a double cantilever beam (DCB) specimen. The treatment generally follows the approach by Kanninen (1973). This method was also used by Burns and Webb (1970) and by Heide-Jørgensen and Budzik (2018). This method is suitable only when the crack speed is small compared to the $\mathrm{P}$ wave speed of the material, which is the case in the following analysis.

First, following the analysis by Kanninen (1973) using a dynamic beam theory, the energy stored in the specimen $U(a)$ and the volume between the two beams $V_{\mathrm{HF}}(a)$, the energy release rate $G$ and the fracture toughness $K$ are derived as follows

$U(a)=\sigma^{2} \Phi_{\mathrm{a}}$

$V_{\mathrm{HF}}(a)=2 \sigma \Phi_{\mathrm{a}}$

$G=\frac{1}{b} \sigma^{2} \frac{\mathrm{d} \Phi_{\mathrm{a}}}{\mathrm{d} a}$
$K=\sqrt{E G}$

where

$\Phi_{\mathrm{a}}=\frac{b}{E h^{3} \lambda^{3}}\left(\frac{3}{5} \lambda^{3} a^{5}+3 \lambda^{2} H a^{4}+\frac{7}{2} \lambda D a^{3}+F a^{2}\right)$

$D=\frac{\sinh ^{2}(\lambda c)+\sin ^{2}(\lambda c)}{\sinh ^{2}(\lambda c)-\sin ^{2}(\lambda c)}$

$H=\frac{\sinh (\lambda c) \cosh (\lambda c)+\sin (\lambda c) \cos (\lambda c)}{\sinh ^{2}(\lambda c)-\sin ^{2}(\lambda c)}$

$F=\frac{\sinh (\lambda c) \cosh (\lambda c)-\sin (\lambda c) \cos (\lambda c)}{\sinh ^{2}(\lambda c)-\sin ^{2}(\lambda c)}$

$\lambda=1.565 / h$

where $a$ is the crack length, $\sigma$ is the hydraulic pressure, $E$ is the elastic modulus and all the other parameters are shown in Fig. 1a.

The derivation process is similar to the analysis of pointload situation by Kanninen (1973). The distributed stress along the crack flank in the hydraulic-pressured DCB specimen is treated as multiple point loads along the crack flank. The details of the derivation process are in another paper 
(Dong et al. 2019a). It is worth noting that according to Eqs. (3) and (4), the total strain energy has the following relationship with volume: $U(a)=\frac{1}{2} \sigma V_{\mathrm{HF}}(a)$.

Second, considering the whole process of crack initiation, crack propagation and crack arrest for a crack length $a_{\mathrm{i}}<a<a_{r}$, the energy conservation can be expressed as

$U\left(a_{\mathrm{i}}\right)+W_{\sigma}=U(a)+b \int_{a_{\mathrm{i}}}^{a} R(a) \mathrm{d} a+T(a)$

where $R$ is the energy absorption per unit area of crack extension, $T$ is the total kinetic energy of the DCB specimen, $a_{\mathrm{i}}$ is the initial length of the crack, $U$ is the strain energy of the body and $W_{\sigma}$ is the work done by the hydraulic pressure.

It is well known that the value of $R$ (namely the energy release rate $G$ ) increases with crack velocity and begins to increase rapidly when the crack speed approaches Rayleigh wave speed (Fineberg et al. 1991; Sharon et al. 1996; Sharon and Fineberg 1999; Shukla 2006). As the crack speed considered here (a typical average value of $5 \mathrm{~m} / \mathrm{s}$ ) is much smaller than the Rayleigh wave speed of the material (about $1000 \mathrm{~m} / \mathrm{s}$ ), it is reasonable to assume that $R$ remains constant or a static value during the low-speed propagation according to the previous studies mentioned above. Thus, $R$ equals the energy release rate of arrest $G_{\mathrm{a}}$.

$W_{\sigma}$ can be treated as the work done by the pump injecting fluid into the void between the specimen, and is expressed in the form as follows

$W_{\sigma}=\int_{V_{\mathrm{i}}}^{V} \sigma(a) \mathrm{d} V_{\mathrm{HF}}(a)$

where $V(a)$ is the fluid volume between two beams. The difficulty lies in determining $\sigma(a)$ during crack propagation. Here, according to the quasi-static assumption, $\sigma(a)$ keeps decreasing after the initiation, and it reaches the arrest pressure $\sigma_{\mathrm{a}}$ at the arrest crack length of $a_{\mathrm{a}}$. In the real situation, due to the flow of fracturing fluid, the pressure keeps fluctuating near $\sigma_{\mathrm{a}}$ and finally reaches $\sigma_{\mathrm{a}}$. It is appropriate to treat $\sigma_{\mathrm{a}}$ as a constant value $\sigma_{\mathrm{a}}$, when the pressure drop and fluctuation are small compared to $\sigma_{\mathrm{a}}$. In other words, the propagation length is small, which is the case in the following calculation. Substituting $\sigma(a)=\sigma_{\mathrm{a}}$ and Eq. (4) into Eq. (13) we have

$W_{\sigma}=\sigma_{\mathrm{a}}\left(V(a)-V_{\mathrm{i}}\right)=2 \sigma_{\mathrm{a}}^{2} \Phi_{\mathrm{a}}-2 \sigma_{\mathrm{a}} \sigma_{\mathrm{i}} \Phi_{\mathrm{i}}$

Substituting $R(a)=G_{\mathrm{a}}$, Eqs. (3) and (14) into Eq. (12), the total kinetic energy could be expressed as

$T(a)=\sigma_{\mathrm{i}}^{2} \Phi_{\mathrm{i}}+2 \sigma_{\mathrm{a}}^{2} \Phi_{\mathrm{a}}-2 \sigma_{\mathrm{a}} \sigma_{\mathrm{i}} \Phi_{\mathrm{i}}-\sigma_{\mathrm{a}}^{2} \Phi(a)-b G_{\mathrm{a}}\left(a-a_{\mathrm{i}}\right)$.

Now considering the crack arrest at the length $a=a_{\mathrm{a}}$, and combining $\eta=G_{\mathrm{i}} / G_{\mathrm{a}}$ and Eq. (5), we have $\frac{\sigma_{\mathrm{i}}}{\sigma_{\mathrm{a}}}=\sqrt{\eta \frac{\Phi_{\mathrm{a}}^{\prime}}{\Phi_{\mathrm{i}}^{\prime}}}$.
Then, substituting it into Eq. (15), leads to the following expression :

$T_{\mathrm{a}}=\sigma_{\mathrm{a}}^{2}\left(\eta \Phi_{\mathrm{i}} \frac{\Phi_{\mathrm{a}}^{\prime}}{\Phi_{\mathrm{i}}^{\prime}}-2 \sqrt{\eta} \Phi_{\mathrm{i}} \sqrt{\frac{\Phi_{\mathrm{a}}^{\prime}}{\Phi_{\mathrm{i}}^{\prime}}}+\Phi_{\mathrm{a}}-\left(a_{\mathrm{a}}-a_{\mathrm{i}}\right) \Phi_{\mathrm{a}}^{\prime}\right)$.

By taking $T_{\mathrm{a}}=0, \eta$ could be solved as long as $a_{\mathrm{a}}$ and $a_{\mathrm{i}}$ are given.

Use of the above formulation requires that $a_{\mathrm{a}}$ and $a_{\mathrm{i}}$ be obtained from experimental results. Typical experimental results of the crack tip as a function of time are shown in Fig. 2. A copper foil of $0.05 \mathrm{~mm}$ thickness is pasted on each side of the surface of the specimen to avoid side flow of the fracturing fluid to the crack tip. This treatment ensures that the crack will quickly get arrested after every initiation because it takes some time for the fluid flow to supply the sufficient fracturing pressure. Based on our experimental observations, the copper foil could resist the side flow from the specimen surface within $10 \mathrm{~mm}$ from the crack tip. As it can be seen in Fig. 2, the crack propagates in a stepwise manner during quasi-static propagation. After every arrest, the crack stops for a typical time span of 1-25 ms. During this short-time arrest of the crack, the process zone develops and blunts the crack. The degree of bluntness $\sqrt{\eta}$, could be calculated using Eq. (16). For every jump, the position of initiation $a_{\mathrm{i}}$, the position of arrest $a_{\mathrm{a}}$, and the duration of last arrest $\Delta t$ are extracted. These parameters are then substituted into Eq. (16). The value of $T_{\mathrm{a}}$ is considered zero after the arrest of the crack. Thus, by taking $T_{\mathrm{a}}=0$, the degree of bluntness $\sqrt{\eta}$ can be calculated for every jump and is shown in Fig. 3.

The copper foil might exert some influence on the mechanical behavior of the PMMA specimen, namely the energy release rate, which is analyzed next. The copper foil

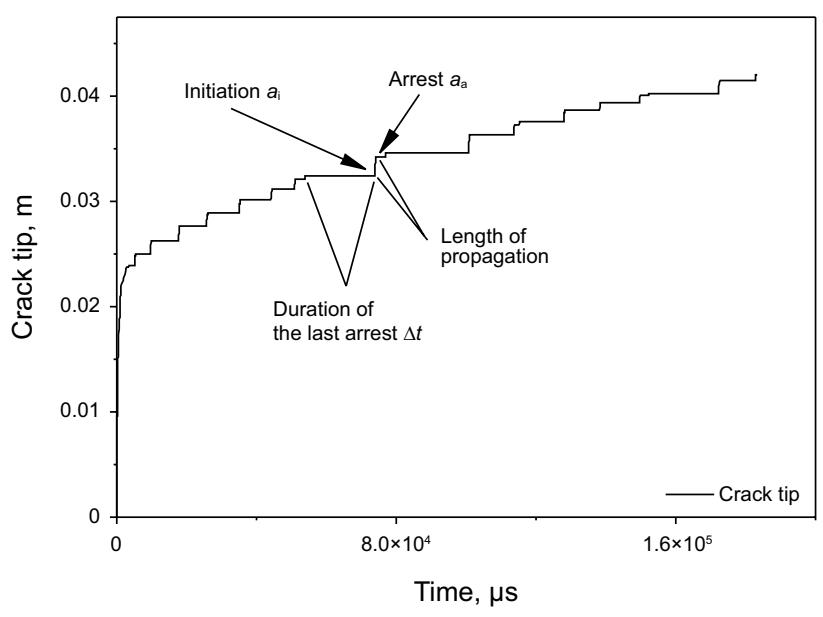

Fig. 2 Typical results of crack tip positions as a function of time in a dynamic situation 


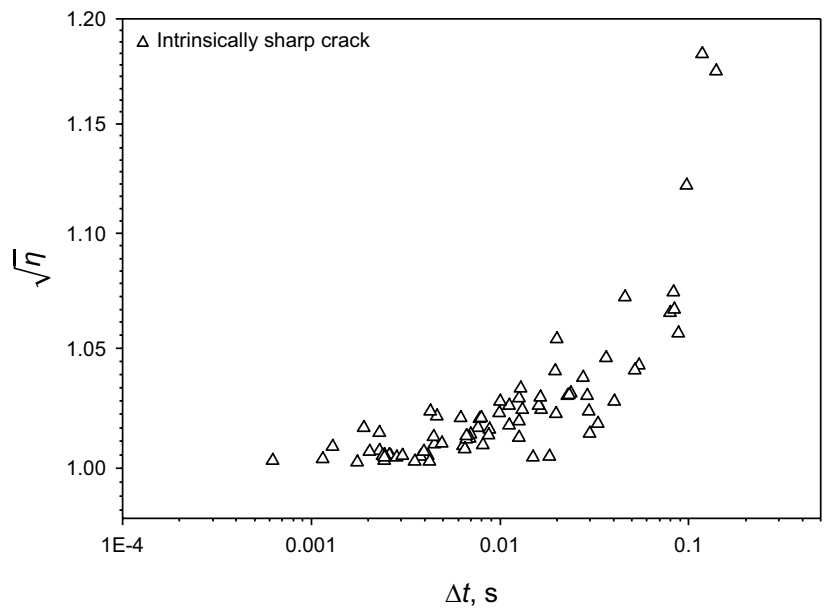

Fig. $3 \sqrt{\eta}$ as a function of blunting time (duration of stress concentration) in dynamic situation

applies a traction force to both crack flanks near the crack tip and increases the energy release rate just like a cohesive zone. The value of $\eta$ derived from Eq. (16) can be written as

$\eta=\frac{G_{\mathrm{Pi}}+G_{\mathrm{C}}}{G_{\mathrm{Pa}}+G_{\mathrm{C}}}$

where $G_{\mathrm{Pi}}$ is the energy release rate of the PMMA specimen and $G_{\mathrm{C}}$ is the energy release rate of the copper foil. By letting the PMMA's real ratio of energy release rate as $\eta^{\prime}=G_{\mathrm{Pi}} / G_{\mathrm{Pa}}$, we have

$\eta^{\prime}=\eta+\frac{G_{\mathrm{C}}}{G_{\mathrm{Pa}}}(\eta-1)$.

Equation (18) suggests that the copper foil has little influence as long as $G_{\mathrm{C}}$ is small compared to $G_{\mathrm{Pi}}$. Moreover, when $\eta$ is slightly larger than $1.0, G_{\mathrm{C}}$ barely exerts any influence on $\eta^{\prime}$. Thus, $\eta$ is directly used here. A brief estimation of the comparison between $\eta^{\prime}$ and $\eta$ is illustrated in Fig. 4. The energy release rate $G$ for both copper foil and PMMA is calculated using Eq. (6). The fracture toughness $K_{\mathrm{C}}$ of copper is $10 \mathrm{MPa} \sqrt{\mathrm{m}}$, the elastic modulus $E_{\mathrm{C}}$ is 120 GPa (Qin et al. 2009) and the total thickness $S_{\mathrm{C}}$ is $0.1 \mathrm{~mm}$. The fracture toughness (arrest toughness $K_{\mathrm{Pa}}$ ) of PMMA is $1 \mathrm{MPa} \sqrt{\mathrm{m}}$ based on regular DCB tests, the elastic modulus $E_{\mathrm{P}}$ is $2.6 \mathrm{GPa}$ and the thickness $S_{\mathrm{E}}$ is $5 \mathrm{~mm}$. Thus, the value of $G_{\mathrm{C}} / G_{\mathrm{Pa}}$ is expressed as follows based on Eq. (6):

$\frac{G_{\mathrm{C}}}{G_{\mathrm{Pa}}}=\frac{K_{\mathrm{C}}^{2} E_{\mathrm{P}} S_{\mathrm{C}}}{E_{\mathrm{C}} K_{\mathrm{Pa}}^{2} S_{\mathrm{p}}}$

The estimated value of $G_{\mathrm{C}} / G_{\mathrm{Pa}}$ is 0.044 according to Eq. (19). As it can be seen in Fig. $4, \eta^{\prime}$ and $\eta$ are only slightly different over the range investigated.

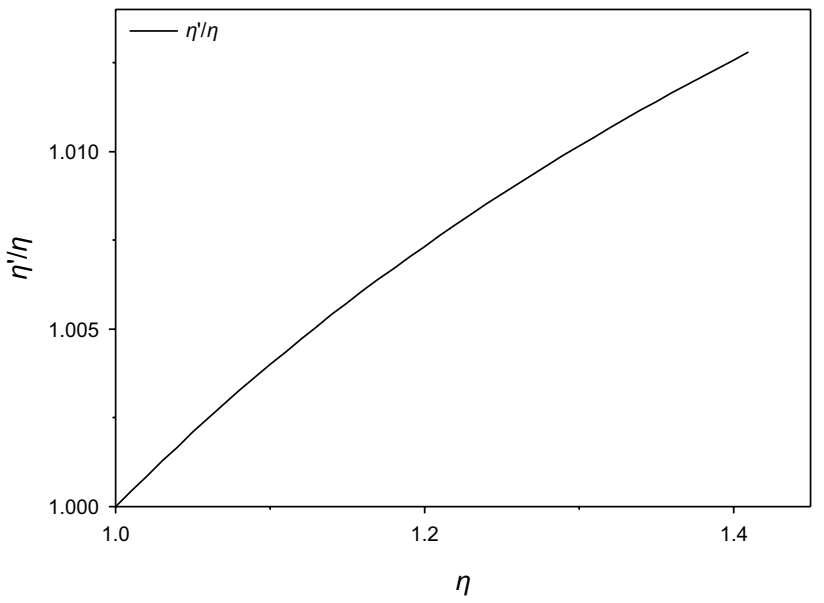

Fig. $4 \eta^{\prime} / \eta$ as a function of $\eta$

As it can be seen, the degree of bluntness $\sqrt{\eta}$ increases with the duration of arrest. One could conclude from these results that in a hydraulic fracture, the crack is blunted at the timescale of $1 \mathrm{~ms}$. At the small timescale, the longer the crack arrests, the more the crack is blunted.

\subsection{Long-time static stress concentration}

To study crack blunting due to long-time stress concentration under hydraulic pressure, the fracture toughness values of both intrinsically sharp crack and $0.5-\mathrm{mm}$ notch crack subjected to long-time pressure hold were measured. The intrinsically sharp crack was induced using Chevron notch using a DCB machine, after which the DCB specimen with a intrinsically sharp crack was subjected to $1.0 \mathrm{MPa}$ pressure (about $67 \%$ of fracturing pressure) and the pressure was held for some time. The pressure applied to $0.5-\mathrm{mm}$ notch crack was $2.0 \mathrm{MPa}$ (about $74 \%$ of the fracturing pressure). Then the specimens were quickly fractured. The typical pressurehold times were 6, 60 and $600 \mathrm{~s}$. The fracture toughness was calculated using Eq. (6). In order to obtain the value of $\sqrt{\eta}=K_{\mathrm{i}} / K_{\mathrm{a}}$, the arrest toughness $K_{\mathrm{a}}$ of the intrinsically sharp crack was measured using a DCB test. The tensile force at the arrest of the crack after a slow and short distance propagation was used to calculate the arrest toughness. The average value of the arrest toughness $K_{\mathrm{a}}$ is $1.0 \mathrm{MPa} \sqrt{\mathrm{m}}$. All the HF-DCB test results are listed in Table 1. All the results of the bluntness $\sqrt{\eta}$ subject to long-time and shorttime stress concentration are shown in Fig. 5.

As it can be seen in Fig. 5, both the intrinsically sharp crack tips and the crack tips of $0.5 \mathrm{~mm}$ notch width exhibit significant blunting due to the stress concentration induced by hydraulic pressure. The blunting of crack tip of HF results from stress the shielding by the process zone in 
Table 1 Summary of test results including statistical parameters

\begin{tabular}{|c|c|c|c|c|c|c|}
\hline & Notch width & $\begin{array}{l}\text { Pressure-hold } \\
\text { duration, s }\end{array}$ & $\begin{array}{l}\text { Hydraulic pres- } \\
\text { sure, } \mathrm{MPa}\end{array}$ & $\begin{array}{l}\text { Average } K_{\mathrm{i}}, \mathrm{MPa} \\
\sqrt{\mathrm{m}}\end{array}$ & Standard deviation & $\begin{array}{l}\text { Number } \\
\text { of tests }\end{array}$ \\
\hline \multirow[t]{6}{*}{ HF-DCB tests } & \multirow[t]{3}{*}{0.5 -mm notch } & 6 & \multirow[t]{3}{*}{2.0} & 2.60501 & 0.32999 & 10 \\
\hline & & 60 & & 2.97043 & 0.43995 & 4 \\
\hline & & 600 & & 3.14321 & 0.09788 & 5 \\
\hline & \multirow[t]{3}{*}{ Natural sharp crack } & 6 & \multirow[t]{3}{*}{1.0} & 1.94 & 0.04429 & 5 \\
\hline & & 60 & & 2.26 & 0.12882 & 3 \\
\hline & & 600 & & 2.94 & 0.50122 & 5 \\
\hline
\end{tabular}

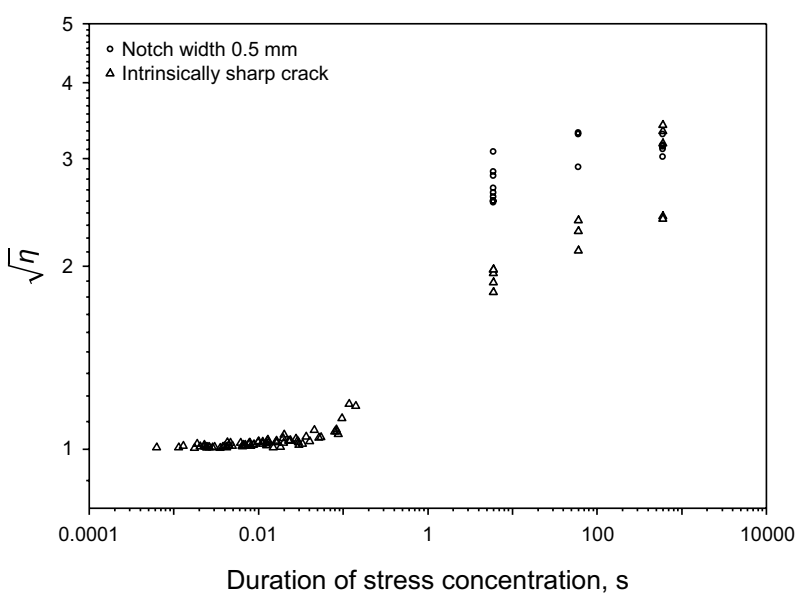

Fig. 5 Summary of $\sqrt{\eta}$ as a function of blunting time (duration of stress concentration), including long-time and short-time blunting, 0.5 -mm notch width cracks and intrinsically sharp cracks

the way of crazing. It is evident from Fig. 5 that even the slightest crazing in hydraulic crack tip exerts a significant influence on fracture toughness of the specimen. The process zone could develop within several milliseconds when the crack tip is subjected to a pressure slightly lower than the fracture pressure, which means that even if we inject hydraulic fluid very fast to fracture the specimen within seconds, the process zone still develops to some degree inevitably.

Based on the observations from this study, the following three factors play a dominant role in the development of a process zone: hydraulic pressure, stress concentration time, and local stress field ahead of the crack tip. The size of the process zone (crazing zone) largely depends on hydraulic pressure. Figure 6 shows the morphology of the craze zone subjected to different hydraulic pressures for $15 \mathrm{~min}$. As it can be seen, the crack tip subjected to $1.0 \mathrm{MPa}$ hydraulic pressure barely exhibits any sign of crazing. The one subjected to 2.0 MPa develops an approximately spherical craze zone of $1 \mathrm{~mm}$ diameter. This phenomenon confirms the results reported by Luo et al. (2014) in which they proposed that crack blunting only occurs when the crack is subjected to tensile fracture stress that is larger than certain value.

As it can be seen in Fig. 7, the process zone grows with time. It is worth noting that this cannot proceed unlimitedly. After blunting for a certain time (typically $10 \mathrm{~min}$ ), the fissures in the process zone tends to stop due to stress relief by the enlargement of the process zone. In other words, the stress intensity factor at every crack tip of the fissures is insufficient to drive the microcrack forward. This leads to the halt of the process zone development.

As it can be seen in Fig. 8, the morphology of the two kinds of crack tips are different. The difference lies in the direction of the microcracks, which results from the difference of the localized stress distribution. The microcracks are always prone to propagate in the direction perpendicular to the direction of minimum principal stress.

Unlike the regular dry crack tip, the process zone in a hydraulic fracture is more prone to develop because the fissures in the process zone are subject to hydraulic pressure as well as the stress concentration induced by the farfield load. The direction of the fissures near the crack tip is controlled by the distribution of near-tip stress. Figure 9 shows the test results of HF-DCB and regular DCB under the same stress concentration duration $(6 \mathrm{~s})$. As it can be seen, the fracture toughness of the HF-DCB specimen is obviously higher than the regular DCB specimen due to the development of process zone. Furthermore, according to our observation, the process zone hardly develops in the regular dry DCB specimen even when the stress intensity factor approaches the fracture toughness. In the previous study, the tip of the hydraulic fracture is often considered as "dry zone". The relationship between the fluid front and the crack tip in dynamic hydraulic fracture was studied by Dong et al. (2019a). In the quasi-static hydraulic, the crack tip is often considered dry due to the viscosity of the fracturing fluid. 

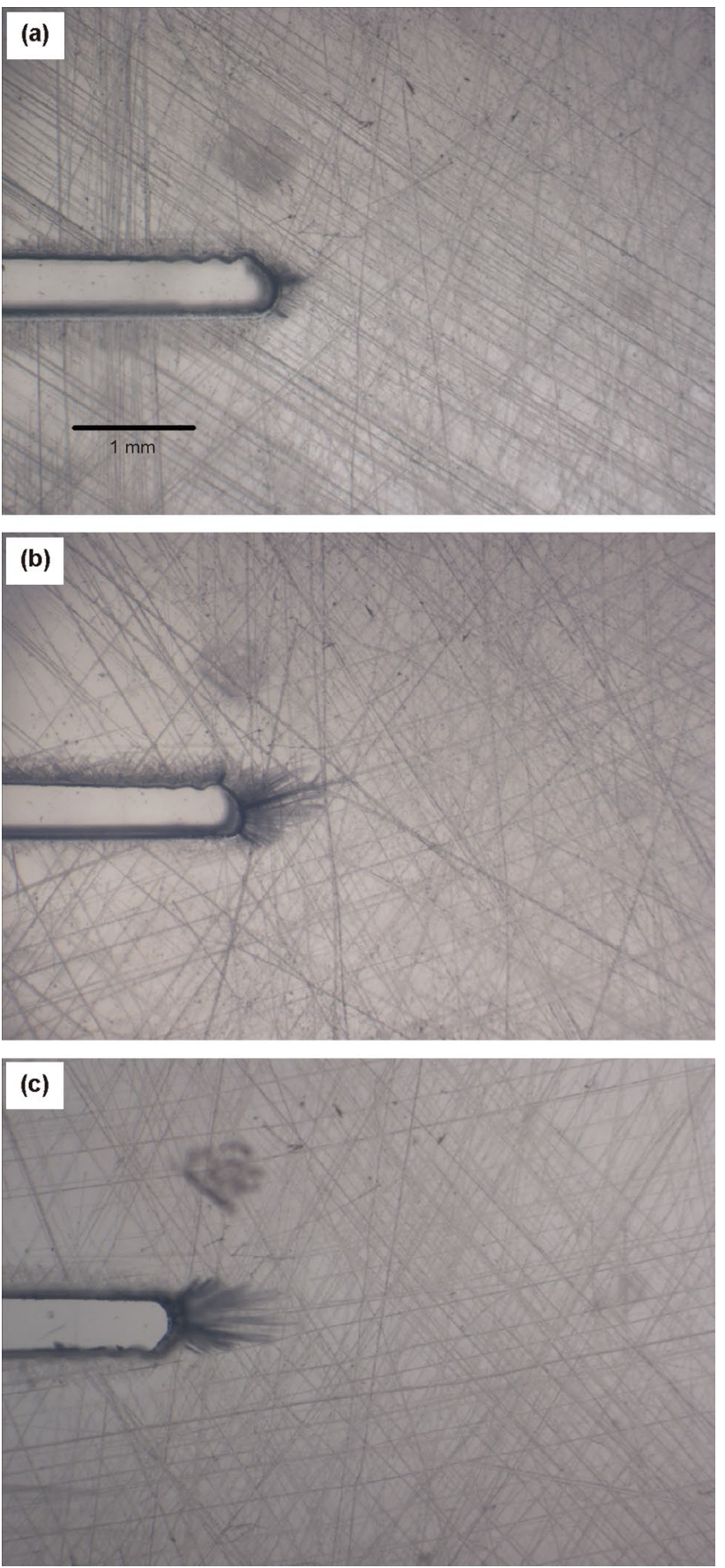

Fig. 6 Process zone subjected to different hydraulic pressures for 15 min. a $1.0 \mathrm{MPa}, \mathbf{b} 1.5 \mathrm{MPa}, \mathbf{c} 2.0 \mathrm{MPa}$. The notch width is $0.5 \mathrm{~mm}$

\section{Discussion}

Crack tip blunting is a highly localized process. We managed to create a quasi-statically propagating crack which curved after initiation due to deviated stress between the horizontal and vertical directions. As it can be seen in Fig. 10d, the process zone is localized within the vicinity of the crack tip and its morphology is mainly influenced by the stress
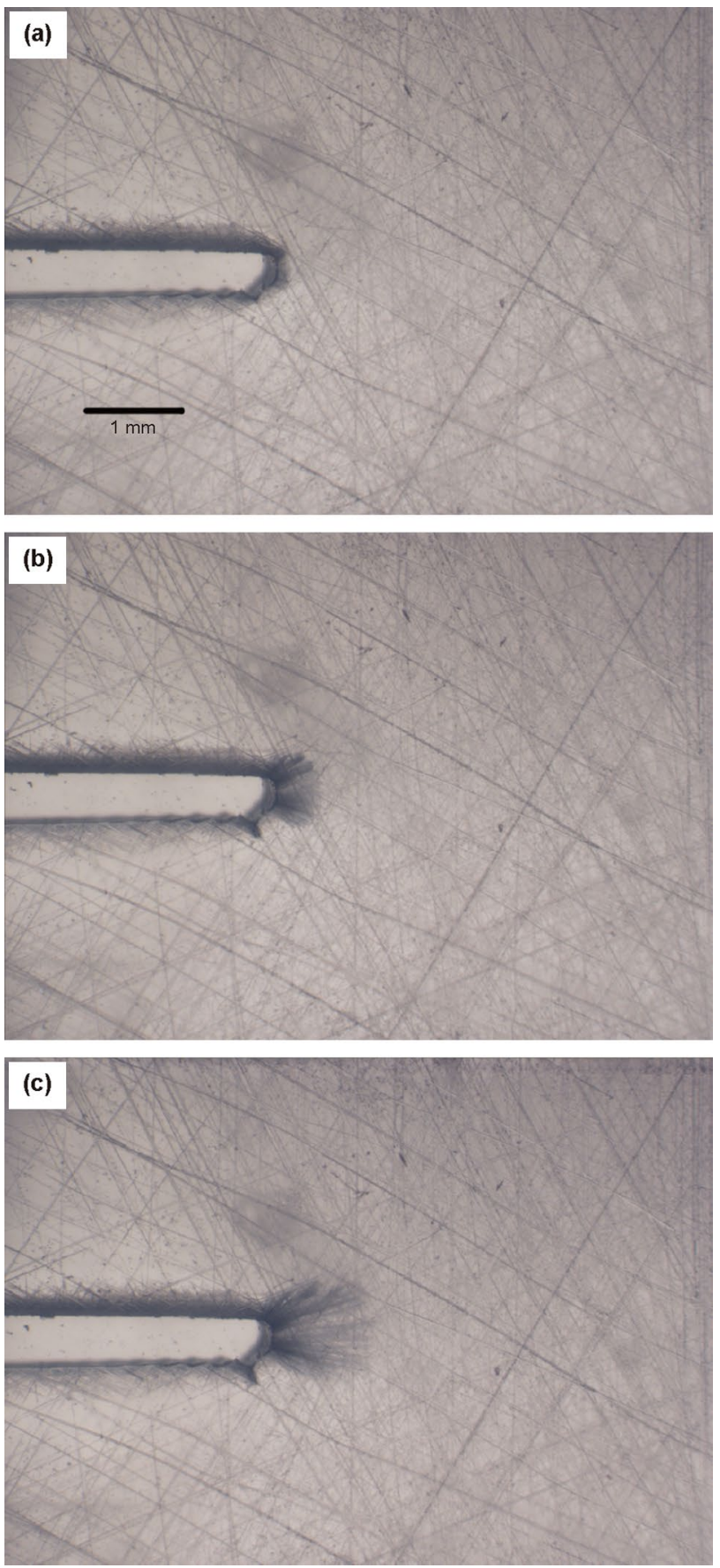

Fig. 7 Development of the process zone at different times. a $5 \mathrm{~s}, \mathbf{b}$ $60 \mathrm{~s}$, c $900 \mathrm{~s}$. The hydraulic pressure is $2.0 \mathrm{MPa}$, the notch width is $0.5 \mathrm{~mm}$

distribution of the crack tip. The far-field stress distribution, namely the deviated stress, seems to exert little influence on the morphology of the process zone.

The general method for crack observation in large-scale 3D hydraulic fracture experiments is using fluorescent dye, which is mixed with the fracturing fluid (Tan et al. 2017). 
(a)
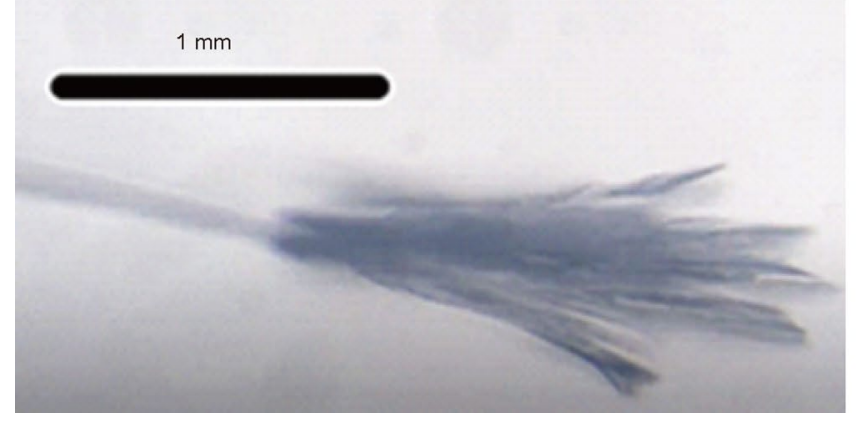

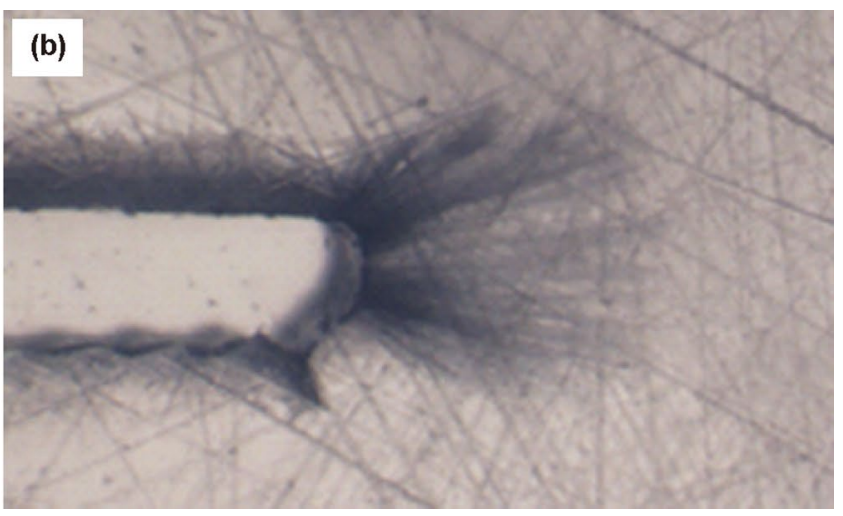

Fig. 8 Development of the process zone due to hydraulic pressure. a $1.0 \mathrm{MPa}$, intrinsically sharp crack tip, $2 \mathrm{~min}, \mathrm{~b} 2.0 \mathrm{MPa}, 0.5 \mathrm{~mm}$ notch width, $15 \mathrm{~min}$

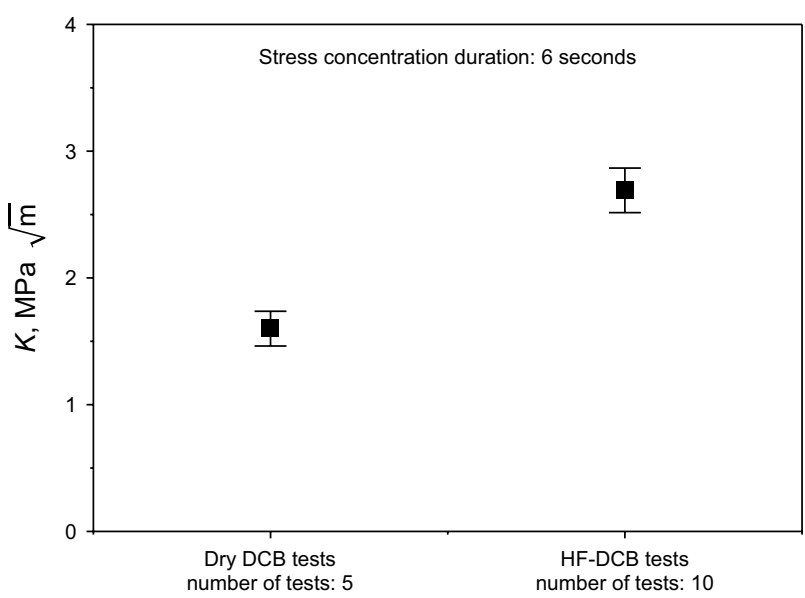

Fig. 9 Comparison of dry DCB tests and HF-DCB tests under the same stress concentration duration

The crack tip is characterized using OM in this study, which is different with general method due to the scale of the experiment. The rock properties also influence the hydraulic fracture. The difference between rock and the PMMA used in this study is that the PMMA is impermeable, which means there is no pore pressure in it. This influence the results to some extent.

The crack blunting due to stress concentration is also seen in rocks such as shale. Figure 11a shows the scanning electron microscope (SEM) photographs of the crack tip area in shale subjected to long-time Mode I stress concentration (regular dry DCB test). Figure $11 \mathrm{~b}$ shows the same area after a short propagation of the crack tip. As it can be seen, the crack tip area subjected to stress concentration exhibits abundant fissures due to the development of process zone induced by long-time stress concentration. It blunts the crack tip in a similar way as the process zone does in hydraulic fracture.
The process zone is also expected in hydraulic fracture propagating in rock matrix. This study only provides results of some limited dimensions. The real hydraulic fracture is on a much larger scale, which could be tens of meters. This study focuses on the microscale properties of the hydraulic fracture, which is on the scale of centimeter. The size effect is not negligible. The process zone in real hydraulic fracture might also be upscaled due to the large size of the fracture. The size of the process zone in the real case is expected to be much larger than the laboratory-scale results. The size depends on the in situ stress, the pressure of fracturing fluid, the dimension of the hydraulic fracture and the mechanical properties of the rock materials. Due to the existence of the in situ stress and the fracturing fluid, the size of the process zone may not be a material constant as linear elastic fracture mechanics (LEFM) tells us. The high-pressure fracturing fluid also enhance the complexity of the microcracks, which makes up the process zone. On the other hand, in reality the rocks are usually saturated with hydrocarbons and that develops poroelastic effects. The poroelastic effects can alter the behavior of the hydraulic fractures significantly as shown by Salimzadeh et al. (2017). The experiments on the poroelastic geomaterial are to be conducted in the further study.

In the real fracturing process, multi-fracture is often expected. The crack blunting not only exerts influence on single crack, but also plays a role in multi-fracture propagation. The most important parameter that affects the multifracture propagation is the ratio of characteristic size of the process zone to the characteristic size of the distance between the fractures. When this dimensionless value is small, the effect of blunting on the interaction can therefore be ignored. When this parameter is relatively large, the blunting area has a different stress distribution compared to the LEFM solution and therefore influences the initiation, propagation and the stress distribution of other fractures. Further in situ observation is needed to investigate 

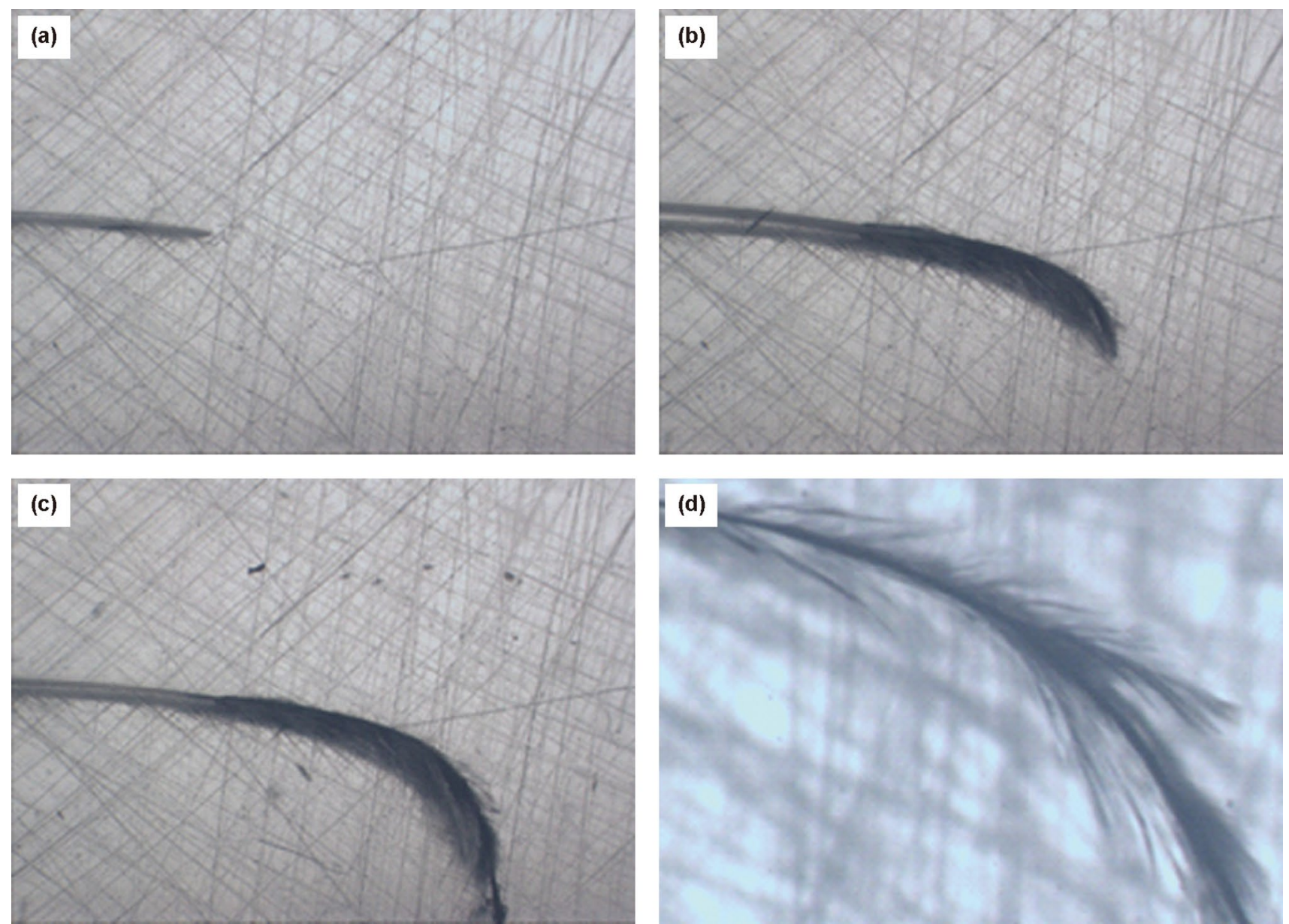

Fig. 10 Curving of hydraulic fracture due to deviated stress. The principal stress is in the vertical direction. a Initiation, $\mathbf{b}$ curving, $\mathbf{c}$ crack direction perpendicular to the minimum principal stress, and $\mathbf{d}$ morphology of the process zone
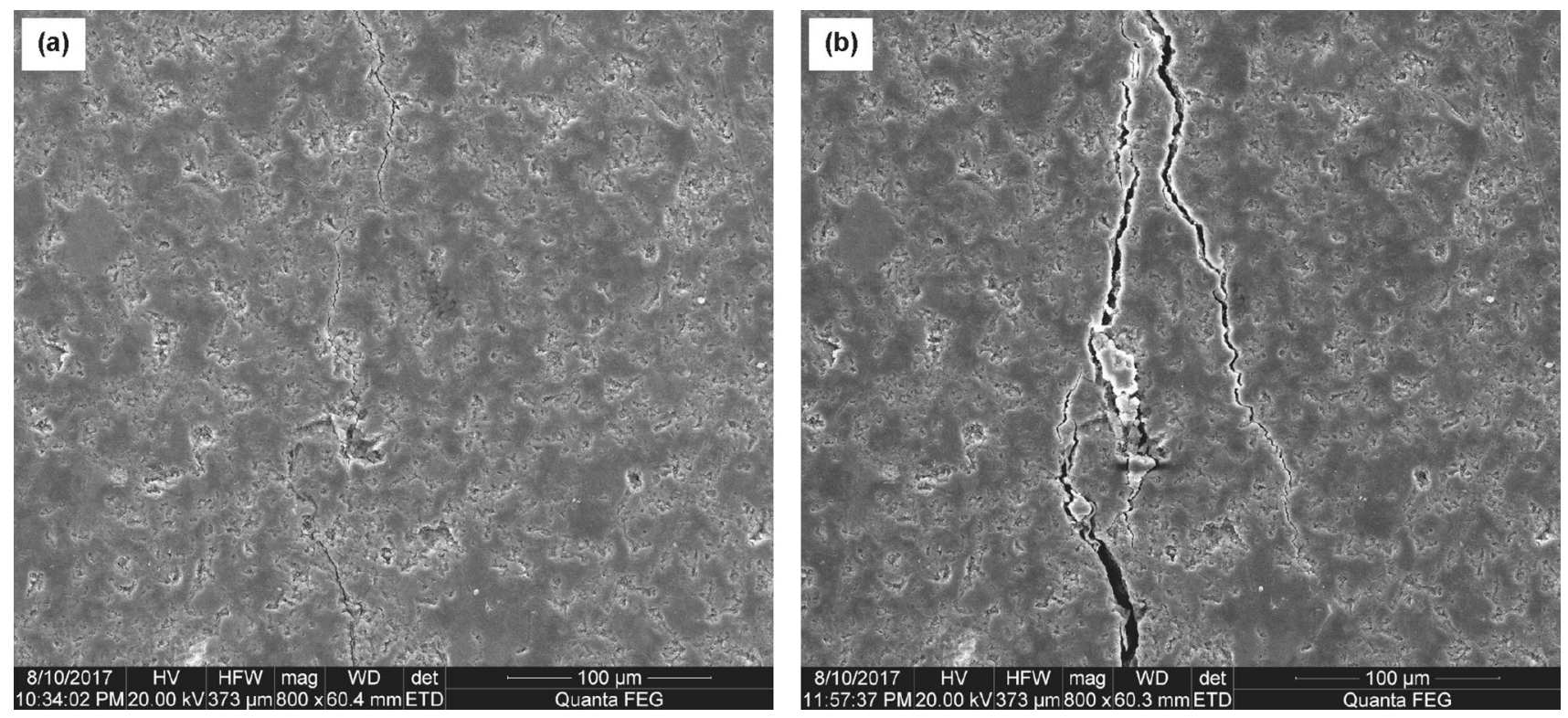

Fig. 11 Crack tip of a shale sample with abundant fissures subjected to stress concentration. a Crack tip area subjected to stress concentration, and $\mathbf{b}$ the same area after a short propagation of the crack tip 
the influence of the crack blunting on the morphology of the multi hydraulic fracture.

This study provides an experimental guidance to the numerical simulation of hydraulic fracturing process. In traditional numerical methods, the energy release rate of the fracture is set constant. For example, in DEM method (such as PFC), the debonding energy of the bond is a constant determined by the particle radius and the tensile/shear strength. This study tells us that the energy release rates are different at initiation and propagation of the fracture. Thus, the energy consumed by the debonding process should be set different values at different stages of the propagation. As is shown in Fig. 5, the arrest time also affects the energy release rate as well as the fracture toughness. Thus, in numerical simulation, the toughness and the energy release rate should be values depending on the status of the crack.

\section{Conclusions}

In this study, the blunting of the hydraulic fracture in PMMA specimens due to multi-timescale stress concentration was investigated. The initiation toughness of the blunted hydraulic fracture was measured using both the dynamic beam theory and the static methods of fracture toughness testing. Conclusions can be drawn as follows:

1. The development of the process zone is the main reason for the hydraulic crack blunting. The blunting of the hydraulic fracture is a highly localized process. The morphology of the blunted crack depends on the stress distribution in the vicinity of the crack tip.

2. The hydraulic pressure, the duration of stress concentration and the near-tip stress field are the dominant factors that influence the development of the process zone.

3. A hydraulic fracture can be blunted at the time span from $1 \mathrm{~ms}$ to $600 \mathrm{~s}$.

Acknowledgements The authors acknowledge the support from the China National Science and Technology Major Project "Changning-Weiyuan shale gas development demonstration project" (2016ZX05062), and the support from the China National Petroleum Corporation: "Research on Influencing Factors of Gas Hydrate Sand Production and Experimental Design" (No. CPETQ201921).

Open Access This article is licensed under a Creative Commons Attribution 4.0 International License, which permits use, sharing, adaptation, distribution and reproduction in any medium or format, as long as you give appropriate credit to the original author(s) and the source, provide a link to the Creative Commons licence, and indicate if changes were made. The images or other third party material in this article are included in the article's Creative Commons licence, unless indicated otherwise in a credit line to the material. If material is not included in the article's Creative Commons licence and your intended use is not permitted by statutory regulation or exceeds the permitted use, you will need to obtain permission directly from the copyright holder. To view a copy of this licence, visit http://creativecommons.org/licenses/by/4.0/.

\section{References}

Ai C, Li X, Zhang J, et al. Experimental investigation of propagation mechanisms and fracture morphology for coalbed methane reservoirs. Pet Sci. 2018;15:815-29. https://doi.org/10.1007/s1218 2-018-0252-z.

Anderson TL. Fracture mechanics: fundamentals and applications. Boca Raton: CRC Press; 2005. p. 291-3.

Beltz GE, Lipkin DM, Fischer LL. Role of crack blunting in ductile versus brittle response of crystalline materials. Phys Rev Lett. 1999;82(22):4468-71. https://doi.org/10.1103/PhysRevLet t.82.4468.

Burns SJ, Webb WW. Fracture surface energies and dislocation processes during dynamical cleavage of LiF. I. Theory. J Appl Phys. 1970;41(5):2078-85. https://doi.org/10.1063/1.1659168.

Cao TD, Hussain F, Schrefler BA. Porous media fracturing dynamics: stepwise crack advancement and fluid pressure oscillations. J Mech Phys Solids. 2018;111:113-33. https://doi.org/10.1016/j. jmps.2017.10.014.

Dong J, Chen M, Li Y, Wang S, Zeng C, Zaman M. Experimental and theoretical study on dynamic hydraulic fracture. Energies. 2019a;12(3):397. https://doi.org/10.3390/en12030397.

Dong J, Chen M, Jin Y, et al. Study on micro-scale properties of cohesive zone in shale. Int J Solids Struct. 2019b;163:178-93. https:// doi.org/10.1016/j.ijsolstr.2019.01.004.

Dong J, Yuan G, Yang H, et al. Experimental study on the characterization of hydraulic fracture tip using digital image correlation method. In: The 5th ISRM Young Scholars' symposium on rock mechanics and REIF2019-international symposium on rock engineering for innovative future. International Society for Rock Mechanics; 2020. (in processing).

Fineberg J, Gross SP, Marder M, Swinney HL. Instability in dynamic fracture. Phys Rev Lett. 1991;67(4):457. https://doi.org/10.1103/ PhysRevLett.67.457.

Fischer LL, Beltz GE. The effect of crack blunting on the competition between dislocation nucleation and cleavage. J Mech Phys Solids. 2001;49(3):635-54. https://doi.org/10.1016/S0022 $-5096(00) 00042-9$.

Germanovich LN, Astakhov DK, Mayerhofer MJ, Shlyapobersky J, Ring LM. Hydraulic fracture with multiple segments. I. Observations and model formulation. Int J Rock Mech Min Sci. 1997;34(3-4):97-e1. https://doi.org/10.1016/s1365 -1609(97)00188-3.

Heide-Jørgensen S, Budzik MK. Effects of bondline discontinuity during growth of interface cracks including stability and kinetic considerations. J Mech Phys Solids. 2018. https://doi.org/10.1016/j. jmps.2018.04.002.

Kanninen MF. An augmented double cantilever beam model for studying crack propagation and arrest. Int J Fract. 1973;9(1):83-92.

Kinloch AJ, Williams JG. Crack blunting mechanisms in polymers. J Mater Sci. 1980;15(4):987-96. https://doi.org/10.1007/BF005 52112.

Li Y, Long M, Tang J, Chen M, Fu X. A hydraulic fracture height mathematical model considering the influence of plastic region at fracture tip. Pet Explor Dev. 2020;47:184-95. https://doi.org/10.1016/ S1876-3804(20)60017-9.

Luo F, Sun TL, Nakajima T, Kurokawa T, Zhao Y, Ihsan AB, et al. Crack blunting and advancing behaviors of tough and self-healing 
polyampholyte hydrogel. Macromolecules. 2014;47(17):6037-46. https://doi.org/10.1021/ma5009447.

Pizzocolo F, Huyghe JM, Ito K. Mode I crack propagation in hydrogels is step wise. Eng Fract Mech. 2013;97:72-9. https://doi. org/10.1016/j.engfracmech.2012.10.018.

Qin EW, Lu L, Tao NR, Tan J, Lu K. Enhanced fracture toughness and strength in bulk nanocrystalline $\mathrm{Cu}$ with nanoscale twin bundles. Acta Mater. 2009;57(20):6215-25. https://doi.org/10.1016/j.actam at.2009.08.048.

Radon JC, Branco CM, Culver LE. Crack blunting and arrest in corrosion fatigue of mild steel. Int J Fract. 1976;12(3):467-9.

Rajan VP, Curtin WA. Crack tip blunting and cleavage under dynamic conditions. J Mech Phys Solids. 2016;90:18-28. https://doi. org/10.1016/j.jmps.2016.02.014.

Salimzadeh S, Khalili N. Fully coupled XFEM model for flow and deformation in fractured porous media with explicit fracture flow. Int J Geomech. 2015a;16(4):04015091. https://doi.org/10.1061/ (ASCE)GM.1943-5622.0000623.

Salimzadeh S, Khalili N. A three-phase XFEM model for hydraulic fracturing with cohesive crack propagation. Comput Geotech. 2015b;69:82-92. https://doi.org/10.1016/j.compgeo.2015.05.001.

Salimzadeh S, Paluszny A, Zimmerman RW. Three-dimensional poroelastic effects during hydraulic fracturing in permeable rocks. Int
J Solids Struct. 2017;108:153-63. https://doi.org/10.1016/j.ijsol str.2016.12.008

Sharon E, Fineberg J. Confirming the continuum theory of dynamic brittle fracture for fast cracks. Nature. 1999;397(6717):333.

Sharon E, Gross SP, Fineberg J. Energy dissipation in dynamic fracture. Phys Rev Lett. 1996;76(12):2117. https://doi.org/10.1103/PhysR evB.54.7128.

Shiari B, Miller RE. Multiscale modeling of crack initiation and propagation at the nanoscale. J Mech Phys Solids. 2016;88:35-49. https ://doi.org/10.1016/j.jmps.2015.12.003.

Shukla A. Dynamic fracture mechanics. Singapore: World Scientific; 2006. p. 239.

Tan P, Jin Y, Han K, Hou B, Chen M, Guo X, et al. Analysis of hydraulic fracture initiation and vertical propagation behavior in laminated shale formation. Fuel. 2017;206:482-93. https://doi. org/10.1016/j.fuel.2017.05.033.

Tan P, Jin Y, Yuan L, et al. Understanding hydraulic fracture propagation behavior in tight sandstone-coal interbedded formations: an experimental investigation. Pet Sci. 2019;16:148-60. https://doi. org/10.1007/s12182-018-0297-z. 